\title{
Anualidade orçamentária e contratos administrativos
}

Dissertação de Mestrado apresentada à Banca Examinadora do Programa de PósGraduação em Direito, da Faculdade de Direito da Universidade de São Paulo, como exigência parcial para a obtenção do título de Mestre em Direito, na área de concentração Direito Econômico, Financeiro e Tributário, sob orientação do Professor Associado Dr. José Mauricio Conti.

UNIVERSIDADE DE SÃO PAULO

FACULDADE DE DIREITO

São Paulo - SP

2018 
Rota, Giovanna Montellato Storace

Anualidade orçamentária e contratos administrativos / Giovanna

Montellato Storace Rota ; orientador José Mauricio Conti - São Paulo, 2018.

$175 \mathrm{p}$.

Dissertaçăo (Mestrado - Programa de Pós-Graduação em Direito Direito Econốmico, Financeiro e Tributário) - Faculdade de Direito, Universidade de São Paulo, 2018.

1. Orçamento público. 2. Anualidade orçamentária. 3. Plurianualidade orçamentária. 4. Contratos administrativos. 5. Consensualidade administrativa. I. Conti, José Mauricio, orient. II. Título. 


\section{FOLHA DE APROVAÇÃO}

Nome: ROTA, Giovanna Montellato Storace Rota

Título: Anualidade orçamentária e contratos administrativos

Dissertação apresentada à Faculdade de Direito da Universidade de São Paulo para obtenção do título de Mestre em Direito.

Aprovada em:

\section{Banca Examinadora}

Prof. Dr.

Instituição:

Julgamento:

Prof. Dr.

Instituição:

Julgamento:

Prof. Dr.

Instituição:

Julgamento: 

Para Vítor, companheiro de vida 



\section{Agradecimentos}

Ao Professor José Mauricio Conti pela cuidadosa orientação, pela confiança depositada em mim nas oportunidades acadêmicas com as quais me presenteou e pela inspiração constante no estudo e na pesquisa do Direito Financeiro.

Aos professores Fernando Dias Menezes de Almeida e Carlos Ari Sundfeld, pelas atenciosas observações na banca de qualificação.

Aos meus pais, Andrea e Paulo, pelo exemplo vivo de dedicação ao saber, que é absorvido, construído e propagado.

Ao meu irmão Stefano, por me lembrar da importância daquilo que acreditamos e queremos.

A minha avó Rita, pelo amor e pelo altruísmo.

Às minhas amigas Keryma, Thaís, Paulinha, Tainá, Laís e Paula, pelo interesse, pela motivação e pela certeza de um lugar seguro para rir ou para chorar.

Ao meu companheiro Vítor, pelo incentivo e apoio nos meus desafios e pela felicidade cotidiana que me permite enfrentá-los. 



\section{Resumo}

ROTA, Giovanna Montellato Storace. Anualidade orçamentária e contratos administrativos. 2018. 175 p. Dissertação (Mestrado em Direito Econômico, Financeiro e Tributário) - Faculdade de Direito, Universidade de São Paulo, São Paulo, 2018.

Essa dissertação de mestrado se debruça sobre a relação entre a anualidade orçamentária, enquanto característica peculiar da lei orçamentária, e os contratos administrativos. A pesquisa analisa o conflito entre a vinculação da Administração Pública a esses contratos, notadamente os plurianuais, e a necessidade de autorização legislativa anual, elemento essencial do orçamento público, para a realização das despesas públicas necessárias ao cumprimento das obrigações contratualmente assumidas. Explora-se a noção de orçamento público, discorrendo-se sobre o seu conceito, origem e evolução, bem como a configuração do sistema orçamentário brasileiro e do ciclo orçamentário, de elaboração, execução e controle dos orçamentos públicos. Em seguida, estuda-se a periodicidade orçamentária, no que são tratados aspectos como exercício financeiro e despesas plurianuais, para ponderar sobre a anualidade ou plurianualidade orçamentária e questionar a anualidade orçamentária enquanto princípio ou regra jurídica. Avança-se para apresentar a evolução da teoria do contrato administrativo, posicionando sua inserção na tendência de atuação da Administração Pública pela consensualidade administrativa, marcada, entre outros aspectos, pela ampliação do conceito de legalidade, enquanto meio de controle e vinculação da Administração Pública, de modo a admitir a sua assunção de obrigações pela via dos contratos administrativos. Feitas essas considerações do trabalho, centra-se no exame de direito positivo da relação entre orçamentos públicos e contratos administrativos por meio da análise de disposições das Leis $\mathrm{n}^{\circ} 8.666 / 93, \mathrm{n}^{\circ} 8.987 / 95, \mathrm{n}^{\circ}$ 9.074/95 e no 11.079/04, bem como do Decreto ${ }^{\circ}$ 9.046/17. Após 
destacar a tendência à plurianualidade dos contratos administrativos e a insuficiência do tratamento normativo do ponto de convergência entre anualidade orçamentária e contratos administrativos, o trabalho examina propostas de alterações normativas, formuladas pela doutrina ou em debate no âmbito do Poder Legislativo, como o carry-over, as dotações orçamentárias plurianuais, a inclusão das despesas contratuais dentre as despesas obrigatórias, a atribuição de tratamento privilegiado às despesas contratuais e o projeto de Lei de Qualidade Fiscal. Ao final, retoma-se a questão de pesquisa, observando que os vícios do ciclo orçamentário têm minimizado a manifestação do conflito entre anualidade orçamentária e contratos administrativos e oferecendo considerações críticas e prospectivas ao tratamento da relação entre anualidade orçamentária e despesas públicas decorrentes de contratos administrativos, em especial aqueles cuja duração ultrapasse um exercício financeiro.

Palavras-chave: anualidade orçamentária; plurianualidade orçamentária; orçamento público; contratos administrativos; consensualidade administrativa. 


\section{Abstract}

ROTA, Giovanna Montellato Storace. Budget annuality and administrative contracts. 2018. 175 p. Dissertation (Master of Laws) - Faculty of Law, University of São Paulo, São Paulo, 2018.

This dissertation focuses on the relation between budget annuality, as a public budget's peculiar feature, and administrative contracts. The research explores the conflict between the Public Administration's binding to these contracts, especially the multiannual ones, and the need for annual legislative authorization, as an essential element of the public budget, for the execution of public expenditures required to fulfill these contractual obligations. Is explored the notion of public budget, scanning its concept, origin and evolution, as well as Brazilian budget system and budget cycle, meaning the elaboration, execution and control of public budgets. Then, is studied the budget periodicity, from aspects such as financial year and multi-annual expenditures, considering budget annuality and multi-annuality and questioning whether budget annuality is a principle or legal rule. It advances to present the evolution of the administrative contract theory, positioning it in the administrative consensuality trend, marked, among other aspects, by the extension of legality's concept, as a means of public control and binding, in order to allow the Public Administration to assume obligations through administrative contracts. Considering this, the research focuses on examining the connection between public budget and administrative contracts by analyzing Brazilian laws $\mathrm{n}^{\circ} 8.666 / 93, \mathrm{n}^{\circ} 8.987 / 95, \mathrm{n}^{\mathrm{o}}$ 9.074/95 and $\mathrm{n}^{\circ} 11.079 / 04$, as well as Decree $\mathrm{n}^{\circ}$ 9.046/17. After highlighting the multi-annual administrative contracts trend and the shortcoming normative treatment given to the relation between budget annuality and administrative contracts, the paper examines proposals for normative changes, such as carry-over, multi-annual appropriations, the inclusion of contractual expenditures among 
compulsory expenditures, privilege treatment to contractual expenditures and the Lei de Qualidade Fiscal (Fiscal Quality Law) draft. Finally, the research question is retaken, noting that the flaws in the budget cycle have reduced the manifestation of the conflict between budget annuality and administrative contracts and offering critical and prospective considerations to the treatment of the relation between budget annuality and public expenditures concerning administrative contracts, especially those whose duration exceeds the financial year.

Keywords: budget annuality; multi-annual budget; public budget; administrative contracts; administrative consensuality. 


\section{Sumário}

1. CONSIDERAÇÕES INICIAIS DE PESQUISA ............................... 15

1.1. Justificativa e problema de pesquisa.......................................... 15

1.2. Questões e hipóteses de pesquisa ............................................ 17

1.3. Metodologia de pesquisa ................................................... 18

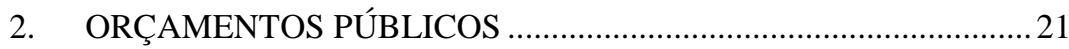

2.1. Conceito de orçamento público ................................................ 21

2.2. Origem e evolução do orçamento público ................................. 22

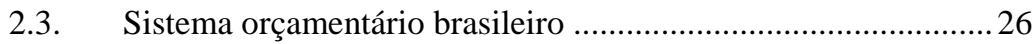

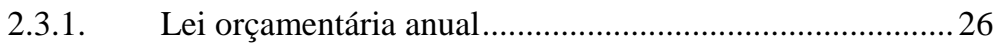

2.3.2. Lei de diretrizes orçamentárias ......................................... 28

2.3.3. Plano plurianual .............................................................. 30

2.3.4. Sistema orçamentário brasileiro e planejamento................ 31

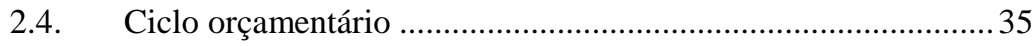

2.4.1. Elaboração das leis orçamentárias .......................................36

2.4.1.1. Fase administrativa...................................................... 36

2.4.1.2. Fase legislativa ..................................................... 47

2.4.2. Execução da lei orçamentária ...........................................53

2.4.2.1. Etapas de execução da despesa pública......................54

2.4.2.2. Instrumentos de flexibilidade da execução

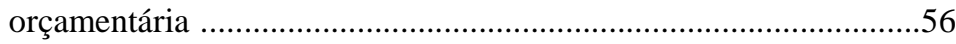

2.4.2.3. Natureza jurídica do orçamento público .....................63 63

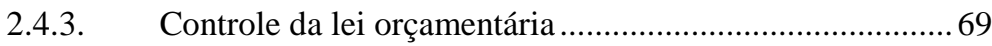

3. ANUALIDADE E PLURIANUALIDADE ORÇAMENTÁRIA .......77

3.1. Anualidade orçamentária .............................................................. 77

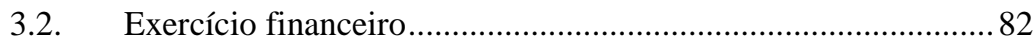

3.3. Regimes de receitas e despesas............................................. 82 


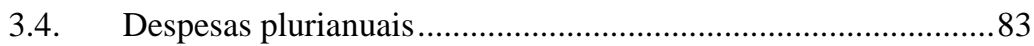

3.4.1. Programas de duração continuada...................................... 85

3.4.2. Despesas obrigatórias de caráter continuado......................87

3.4.3. Créditos especiais e extraordinários .................................... 88

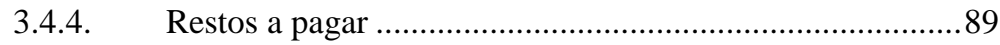

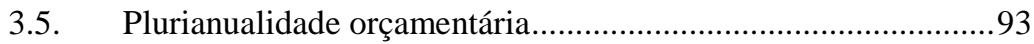

3.6. Anualidade orçamentária: princípio ou regra? ............................99

4. CONTRATOS ADMINISTRATIVOS E CONSENSUALIDADE

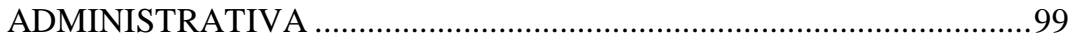

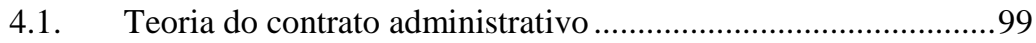

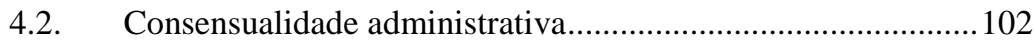

4.3. Legalidade e consensualidade administrativa ............................105

5. ORÇAMENTO PÚBLICO E CONTRATOS ADMINISTRATIVOS

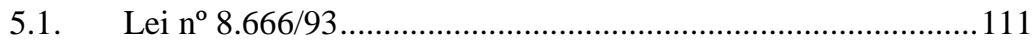

5.2. Concessões (Leis $\mathrm{n}^{\circ} 8.987 / 95, \mathrm{n}^{\circ}$ 9.074/95 e $\mathrm{n}^{\circ}$ 11.079/04) .....121

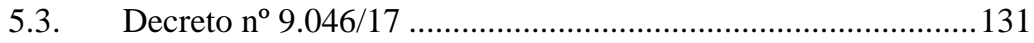

5.4. Duração dos contratos administrativos .................................... 132

6. PROPOSTAS DE ALTERAÇÕES NORMATIVAS ........................135

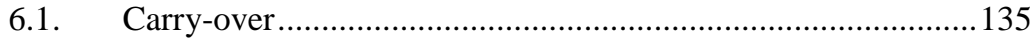

6.2. Dotações orçamentárias plurianuais ........................................... 141

6.3. Despesas contratuais como despesas obrigatórias ....................143

6.4. Tratamento privilegiado das despesas contratuais ...................143

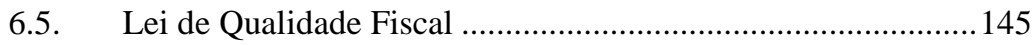

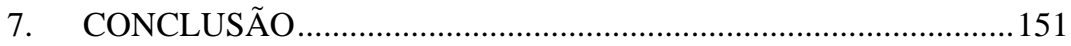

REFERÊNCIAS BIBLIOGRÁFICAS .................................................... 163 


\section{CONSIDERAÇÕES INICIAIS DE PESQUISA}

\subsection{Justificativa e problema de pesquisa}

O presente trabalho encontra-se inserido na linha de pesquisa Direito Financeiro na Constituição e no projeto acadêmico Orçamento Público: planejamento, gestão e controle. Dentro desse parâmetro, a pesquisa recai, em especial, sobre a característica de periodicidade ou anualidade dos orçamentos públicos e sua interação com os contratos administrativos.

Como se trata de uma pesquisa jurídica, há consequente delimitação do tema e do objeto de estudo. Assim, a análise teve por foco a Constituição Federal, os diplomas legais, a doutrina jurídica sobre o tema e os projetos de lei em trâmite no Congresso Nacional que porventura façam modificações relacionadas à anualidade orçamentária atualmente consagrada pelo ordenamento jurídico brasileiro.

O orçamento público propriamente dito e executável consiste na lei orçamentária anual, que possui características peculiares que a distinguem das demais leis. Uma dessas peculiaridades é a sua natureza temporária, ou seja, o fato de que ela possui a validade de somente um exercício financeiro. ${ }^{1}$ No ordenamento jurídico brasileiro, essa periodicidade foi concretizada como anualidade, conforme se observa no artigo 165, III, da Constituição Federal, e no artigo $2^{\circ}$, caput, da Lei no $4.320 / 64$.

Essa anualidade, ao criar a necessidade regular e periódica de que a lei orçamentária seja aprovada pelo Poder Legislativo, ainda confere efetividade à função de controle político do orçamento público e um caráter democrático à autorização de despesas e alocação dos recursos públicos.

\footnotetext{
${ }^{1}$ CONTI, José Mauricio. Orçamento impositivo é avanço para administração. In: Levando o direito financeiro a sério. São Paulo: Blucher, 2016, p. 157.
} 
Contudo, o ordenamento jurídico também prevê a existência do plano plurianual, um instrumento legal de planejamento da ação governamental válido por quatro anos, que deve estabelecer as diretrizes, metas e objetivos da Administração Pública relativos às despesas de capital e às despesas dos programas de duração continuada.

A própria Constituição Federal criou uma relação entre as duas normas, ao determinar, em seu artigo 165 , parágrafo $7^{\circ}$, que “[o]s orçamentos previstos no $\S 5^{\circ}$, I e II, deste artigo, compatibilizados com o plano plurianual, terão entre suas funções a de reduzir desigualdades inter-regionais, segundo critério populacional". Ou seja, há a necessidade de compatibilização dos orçamentos fiscal e de investimentos, compreendidos na lei orçamentária anual, com o plano plurianual.

Isto posto, colocam-se alguns motivos que justificam a realização dessa pesquisa.

Observa-se que a periodicidade ou anualidade da lei orçamentária, enquanto peculiaridade desse tipo de norma, merece uma análise profunda de sua concretização. A anualidade orçamentária é uma construção de natureza jurídica, pois a Administração Pública tem atividade contínua, que não se encerra a cada exercício financeiro. Com isso, nem todas as despesas conseguem ser executadas dentro do exercício financeiro gerando, por exemplo, os restos a pagar. Além disso, existem despesas que, por sua própria natureza, têm duração continuada e superior a um ano, não podendo ser totalmente compreendidas na anualidade orçamentária.

Esse conflito aparece de forma acentuada no caso dos contratos administrativos. A doutrina do Direito Administrativo evolui no sentido de que o contrato vincula a Administração Pública, mitigando as assimetrias de posições jurídicas entre o Poder Público e os particulares nesse tipo de relação e limitando o uso do argumento do "interesse público" pela Administração Pública como escape ao 
cumprimento de obrigações contratuais. ${ }^{2}$ Desse modo, ao celebrar um contrato, a Administração Pública assume uma obrigação e, sendo essa obrigação pecuniária, requer dotações orçamentárias para ser cumprida.

Nesse ponto, tem-se um aspecto de atrito com as normas orçamentárias. Se, por um lado, a Administração Pública, ao celebrar contratos administrativos, assume obrigações, por outro, depende da autorização orçamentária legislativa anual para cumpri-las. A questão se torna ainda mais complexa ao considerar-se os contratos administrativos plurianuais, vez que o processo de autorização das despesas pelo Poder Legislativo deverá ser repetido a cada ano, situação na qual a anualidade orçamentária e os seus limites ficam em evidência.

Esse conflito presente no ordenamento jurídico brasileiro requer um estudo aprofundado, que se objetiva empreender ao longo dessa dissertação. Para tanto, mapeiam-se as normas que regem as despesas plurianuais - ou, ao menos, as despesas que ultrapassam o limite de determinado exercício financeiro - e a relação entre as normas orçamentárias e os contratos administrativos, a fim de analisar os diversos aspectos desse conflito e suas possíveis soluções.

\subsection{Questões e hipóteses de pesquisa}

De acordo com o já exposto, a principal questão que guia o desenvolvimento dessa pesquisa é: como o ordenamento jurídico e a doutrina jurídica lidam com o conflito entre a anualidade orçamentária e os contratos administrativos?

Com base nas pesquisas preliminares, a hipótese de pesquisa é a de que esse conflito não tem uma solução definida pelo

\footnotetext{
2 MARQUES NETO, Floriano de Azevedo. Do contrato administrativo à administração contratual. In: Revista do Advogado, São Paulo: Associação dos Advogados de São Paulo, ano XXIX, nº 107, p. $74-82$, dez. 2009.
} 
ordenamento jurídico e não é abordado diretamente pela doutrina jurídica.

Assim, a pesquisa também será norteada por outras questões acessórias: qual a importância da autorização legislativa no sistema orçamentário brasileiro?, qual o papel do Poder Legislativo no ciclo orçamentário?, como o ordenamento jurídico e a doutrina tratam a anualidade orçamentária?, como o ordenamento jurídico brasileiro regula as despesas plurianuais?, como o ordenamento jurídico e a doutrina tratam a vinculação da Administração Pública aos contratos administrativos? e como o ordenamento jurídico e a doutrina tratam a relação entre o orçamento público e os contratos administrativos?

$\mathrm{Na}$ busca pelas respostas dessas questões espera-se determinar os pontos principais do conflito entre a anualidade orçamentária e os contratos administrativos plurianuais e encontrar parâmetros para lidar com esse conflito.

\subsection{Metodologia de pesquisa}

A metodologia dessa pesquisa consiste no levantamento, leitura e análise dos diplomas legais e dos textos doutrinários sobre os temas a serem explorados, em especial documentos que abordem (a) o planejamento governamental e a relação entre as leis orçamentárias (plano plurianual, lei de diretrizes orçamentária e lei orçamentária anual), (b) a participação do Poder Legislativo no ciclo orçamentário, (c) a anualidade orçamentária, (d) a vinculação da Administração Pública a obrigações oriundas de contratos administrativos, (e) a relação entre orçamento público e contratos administrativos.

Convém registrar que não foram incluídas no objeto de pesquisa decisões judiciais e administrativas, vez que a atividade de controle exercida pelo Poder Judiciário e pelos Tribunais de Contas sobre o orçamento público ainda é fenômeno incipiente, predominando, nessa função o controle político do Poder Legislativo.

Os diplomas normativos considerados nessa pesquisa foram a Constituição Federal, inclusive o Ato das Disposições Constitucionais Transitórias (ADCT), a Lei $\mathrm{n}^{\circ}$ 4.320/64, a Lei 
Complementar $n^{\mathbf{0}}$ 101/00 (Lei de Responsabilidade Fiscal), as leis que regulam os contratos administrativos incluídos no escopo do estudo $\left(\right.$ Lei $^{\circ}$ 8.666/93, Lei ${ }^{\circ}$ 8.987/95, Lei n ${ }^{\circ}$ 9.074/95 e Lei $\left.{ }^{\circ}{ }^{11} .079 / 04\right),{ }^{3}$ e algumas normas infralegais que serão pontuadas ao longo da dissertação. Também foi analisado o Projeto de Lei Complementar $n^{\circ}$ 295/16 da Câmara dos Deputados (antigo Projeto de Lei Complementar $n^{\circ} 229 / 09$ do Senado Federal), conhecido como projeto da Lei de Qualidade Fiscal, que pretende substituir a Lei $n^{\circ}$ 4.320/64 e alterar a Lei Complementar $n^{\circ} 101 / 00$.

Os livros jurídicos foram selecionados a partir do sistema Dedalus da Universidade de São Paulo, os artigos científicos publicados em periódicos jurídicos foram selecionados a partir da base de dados Ius Data da Faculdade de Direito da Universidade de São Paulo e as dissertações de mestrado e teses de doutorado foram selecionadas na Biblioteca Digital Brasileira de Teses e Dissertações do Instituto Brasileiro de Informação em Ciência e Tecnologia, sem prejuízo de demais materiais de outras fontes que se mostraram relevantes para a pesquisa, especialmente coletâneas de artigos no formato de livros, que não aparecem nas bases bibliográficas utilizadas. Todas as pesquisas nos bancos de dados foram atualizadas até 24 de outubro de 2017.

No sistema Dedalus foi utilizado o termo "orçamento público", em "todos os campos", na base para busca na Faculdade de Direito, gerando 202 resultados. Também foi utilizado o termo "contrato administrativo", gerando 220 resultados. Desses resultados, os livros relevantes foram selecionados a partir do título, da indexação de assuntos do sistema Dedalus e, em alguns casos, do índice do livro. O termo "direito financeiro" foi descartado por gerar um número muito grande de resultados. Em contrapartida, foram incluídos no material de pesquisa todos os manuais ou livros clássicos gerais sobre

\footnotetext{
${ }^{3}$ Embora essas não sejam as únicas leis que regem contratos administrativos, na concepção do termo adotada nesse trabalho, tais leis foram selecionadas por sua relevância na organização da atividade contratual da Administração Pública, refletida na especial atenção dada pela doutrina a essas espécies contratuais.
} 
a disciplina disponíveis na Biblioteca Departamental de Direito Econômico, Financeiro e Tributário ou na Biblioteca Circulante da Faculdade de Direito da Universidade de São Paulo que não constaram dos resultados pelo termo "orçamento público".

No sistema Ius Data foram utilizados os termos "direito financeiro", "orçamento" e "contrato administrativo" em "todos os campos" nos idiomas português, inglês, francês e espanhol, que geraram, respectivamente, 336, 274 e 828 resultados. Desses resultados, os artigos científicos relevantes foram selecionados a partir do título e da indexação de assuntos do sistema Ius Data.

A escolha pelo uso de termos abrangentes como "direito financeiro", "orçamento", "orçamento público" e "contrato administrativo" na opção "todos os campos" nos sistemas Dedalus e Ius Data teve por fundamento a observação de que o uso de termos mais específicos, como "anualidade orçamentária", ou a seleção de campos determinados, como "título" ou "assunto", tinha resultados de pesquisa muito restritos e não selecionava textos doutrinários relevantes para o trabalho. Assim, após a escolha dos livros e artigos científicos resultantes das pesquisas com os termos "direito financeiro", "orçamento" e "orçamento público" os textos foram divididos e agrupados pelo tema a que se referem, como "sistema orçamentário", "ciclo orçamentário" ou "anualidade orçamentária", para organizar a leitura e análise do material.

No sistema da Biblioteca Digital Brasileira de Teses e Dissertações do Instituto Brasileiro de Informação em Ciência e Tecnologia, foi utilizado o termo "orçamento", com o filtro para Programas de Pós-Graduação em "Direito", e foram obtidos 97 resultados. Desses resultados, as dissertações de mestrado e teses de doutorado foram selecionadas a partir do título, da indexação de assuntos e, quando disponível, do resumo do trabalho. Em razão da indexação de assuntos do sistema, não foi possível utilizar o termo de busca "orçamento público", pois excluiria resultados relevantes. 


\section{CONCLUSÃO}

Desenvolvido o quanto proposto para esse trabalho, é possível avaliar as possíveis respostas para as questões de pesquisa e se as respectivas hipóteses foram confirmadas.

A questão principal para esse trabalho era como o ordenamento jurídico e a doutrina jurídica lidam com o conflito entre a anualidade orçamentária e os contratos administrativos?

Em primeiro lugar, deve-se considerar que essa pergunta tinha uma premissa: existe um conflito entre anualidade orçamentária e contratos administrativos. Ao longo do trabalho de pesquisa, podese dizer que essa premissa foi confirmada, contudo, em graus variados, a depender do tipo contratual em questão, o que será abordado nessa conclusão.

Esse conflito pode ser resumido da seguinte forma: os contratos administrativos celebrados pela Administração Pública a vinculam e, a depender do caso, geram compromissos financeiros que ela deverá cumprir. Contudo, para tanto, a Administração Pública depende de uma dotação orçamentária que consigne uma autorização dada pelo Poder Legislativo durante o processo orçamentário para a execução da respectiva despesa pública.

A hipótese de pesquisa era a de que esse conflito não tem solução definida pelo ordenamento jurídico e não é abordado diretamente pela doutrina jurídica. Entende-se que a hipótese de pesquisa tenha se confirmado apenas em parte.

De fato, não há uma solução definida pelo ordenamento jurídico, mas ele não é totalmente alheio ao conflito e tem disposições normativas para regular algumas das suas facetas. Já a doutrina jurídica não aborda o conflito na sua integralidade de forma direta, mas existem estudos que tratam dos seus efeitos e são vários os trabalhos que tratam da duração dos contratos regidos pela Lei $n^{\circ}$ 8.666/93, um dos pontos centrais de convergência entre a anualidade orçamentária e os contratos administrativos. 
Ademais, para o estudo desse conflito, foram estabelecidas outras questões de pesquisa, para as quais se tentará formular respostas.

As primeiras perguntas são: qual a importância da autorização legislativa no sistema orçamentário brasileiro? e qual o papel do Poder Legislativo no ciclo orçamentário?

Nessa pesquisa, ficou estabelecido que o orçamento público é um instrumento de controle político do Poder Legislativo sobre a Administração Pública, mas também um instrumento de planejamento da atuação estatal.

A autorização legislativa compõe o próprio conceito de orçamento público e é a periodicidade orçamentária, que foi consagrada como anualidade, que permite ao Poder Legislativo revisar o orçamento público e conceder a sua autorização para a realização de despesas públicas na forma de dotações orçamentárias na LOA.

Além da autorização legislativa, o Poder Legislativo ainda tem papel fundamental no controle político da execução orçamentária, em razão de suas competências na autorização e limitação do uso dos instrumentos de flexibilidade orçamentária, que visa a resguardar a própria autorização legislativa orçamentária.

Ainda, a LOA insere-se dentro de um sistema orçamentário, composto também por PPA e LDO, que reforça a função de planejamento do orçamento público, tendo em vista a orientação do ordenamento jurídico para a formulação das leis orçamentárias a fim de estabelecer objetivos e metas para a Administração Pública, com aval do Poder Legislativo, em função dos quais será elaborada a LOA e serão concedidas as dotações orçamentárias.

Não obstante a participação do Poder Legislativo no ciclo orçamentário seja central para que o orçamento público possa exercer as suas funções, verificou-se que essa centralidade não tem se refletido na prática. O Poder Legislativo tem se omitido durante o ciclo orçamentário, limitando a sua participação na elaboração das leis orçamentárias à inclusão de emendas parlamentares em cotas préreservadas na LOA e permitindo ampla liberdade ao Poder Executivo 
no uso dos instrumentos de flexibilidade orçamentária no momento de sua execução.

Esse cenário tem estimulado doutrinadores a defenderem maior participação do Poder Legislativo na elaboração das leis orçamentárias e, em especial, a natureza impositiva da LOA, de modo a encará-la como lei em sentido material, a ser cumprida nos termos em que foi aprovada, resgatando-se a essencialidade da autorização legislativa orçamentária e potencializando a função de planejamento das leis orçamentárias.

Avançando no trabalho, foram exploradas as questões como $o$ ordenamento jurídico e a doutrina tratam a anualidade orçamentária? e como o ordenamento jurídico brasileiro regula as despesas plurianuais?

Viu-se que a Lei $n^{\circ} 4.320 / 64$ refere-se à anualidade orçamentária como princípio, mas que a Constituição Federal a adota como o próprio prazo de vigência da LOA. A doutrina, por sua vez, é quase unânime em nomeá-la como princípio orçamentário. A partir da distinção teórica entre regras e princípios, defendeu-se o tratamento da anualidade orçamentária como regra, a admitir exceções, sem que isso retire seu caráter fundamental e estruturador das finanças públicas proposto pela doutrina ao considerá-la princípio.

Por sua vez, o próprio ordenamento jurídico concebe a existência de despesas que ultrapassam um exercício financeiro e prevê exceções à anualidade orçamentária.

Nesse tema, tem-se as despesas relativas a programas de duração continuada, que devem constar do PPA, e as despesas obrigatórias de caráter continuado, para as quais há especial atenção da LRF. Falando-se propriamente das exceções à anualidade orçamentária, destacam-se os restos a pagar, na medida em que permitem que parte da execução da despesa seja realizada em exercício financeiro diverso daquele para o qual foi autorizada, e a possibilidade de reabertura, no exercício financeiro seguinte, de 
créditos especiais e extraordinários autorizados nos últimos quatro meses do exercício financeiro.

Essa última é, de fato, a maior exceção à anualidade orçamentária - a única, se considerado apenas o âmbito da autorização legislativa -, vez que permite que não somente a execução da despesa, mas a própria autorização legislativa para sua realização seja carregada para outro exercício financeiro.

Por fim, é possível relacionar os orçamentos públicos aos contratos administrativos, a partir das questões como o ordenamento jurídico e a doutrina tratam a vinculação da Administração Pública aos contratos administrativos? e como o ordenamento jurídico e a doutrina tratam a relação entre o orçamento público e os contratos administrativos?

Observou-se uma evolução na teoria do contrato administrativo em um contexto de consensualidade administrativa, para reduzir as disparidades entre Administração Pública e particular no âmbito dos contratos, de modo que a Administração Pública fique vinculada de forma mais marcante às obrigações contratualmente contraídas, diminuindo-se o manejo das cláusulas exorbitantes e aumentando-se a observância aos termos contratuais e aos direitos do particular contratado.

A partir disso, foram estudadas leis que regem contratos administrativos para verificar que, na regra da Lei $n^{\circ}$ 8.666/93 - que positiva a formulação originária da teoria do contrato administrativo permeado por cláusulas exorbitantes -, os contratos administrativos devem se conformar à anualidade orçamentária, que limita a sua duração, apesar das amplas exceções previstas na norma.

Além disso, foram considerados os impactos orçamentários resultantes do uso das cláusulas exorbitantes, em especial da alteração do contrato pela Administração Pública. Esses impactos orçamentários também são relevantes nos casos em que a Administração Pública não pode cumprir com suas obrigações pecuniárias contratuais por ausência de dotação orçamentária, situação possível de se manifestar nas exceções à regra de limitação da duração 
do contrato à vigência anual das dotações orçamentárias do exercício financeiro de celebração do contrato.

Nas leis que regulam concessões não há mais a limitação da duração contratual à anualidade orçamentária, notadamente pela inadequação de tal regra ao objeto desses contratos.

Para os contratos regidos pelas Leis $n^{\circ} 8.987 / 95$ e $n^{\circ}$ 9.074/95, soma-se o fato de que tais concessões foram estruturadas de modo que a remuneração do particular se desse por meio de tarifas pagas pelos usuários dos serviços públicos e não pela Administração Pública. Em razão dessa concepção de que esses tipos contratuais não criariam obrigações pecuniárias para a Administração Pública, as leis que os regulam não trataram de questões orçamentários.

Entretanto, essas concessões podem ter impactos orçamentários, nos casos de adequação do equilíbrio econômicofinanceiro decorrente de alterações contratuais ou nas hipóteses de remuneração por parte da Administração Pública com vistas à modicidade ou outros benefícios tarifários.

Já na Lei no 11.079/04, que regula as PPPs, há um cuidado com a previsão e limitação do comprometimento de receitas com esses contratos, a fim de garantir a existência de recursos futuros e minimizar o fato de que sua celebração antecede a dotação orçamentária necessária ao seu cumprimento pela Administração Pública. Além disso, destaca-se a exigência de consonância dos projetos viabilizados por esses contratos administrativos com o sistema orçamentário.

Unindo todas essas questões, para retomar o ponto principal da pesquisa, é possível identificar que o problema das despesas públicas relativas aos compromissos financeiros assumidos pela Administração Pública pela via contratual, embora conceitualmente centrado na autorização legislativa, se apresenta em todos os momentos do ciclo orçamentário.

No momento atual, esse conflito parece se resolver exatamente por meio dos vícios do orçamento público. 
O modelo de orçamento incremental, adotado na elaboração das leis orçamentárias brasileiras, garante que as despesas relativas aos contratos administrativos sejam anualmente renovadas e incluídas no projeto de LOA. A inércia do Poder Legislativo na elaboração das leis orçamentárias faz com que o projeto de LOA encaminhado pelo Poder Executivo seja aprovado sem discussões e alterações para além das cotas para emendas parlamentares, garantindo que os contratos administrativos recebam as suas respectivas dotações orçamentárias. Em último caso, ainda que as dotações orçamentárias necessárias ao cumprimento das obrigações contratuais assumidas pela Administração Pública não constem da LOA, a Administração Pública pode recorrer aos instrumentos de flexibilidade orçamentária para abrir créditos adicionais e realizar essas despesas.

Por outro lado, se já incluídas na LOA, as despesas relativas aos contratos administrativos são prejudicadas pelo uso dos instrumentos de flexibilidade orçamentária na medida em que têm sua execução postergada e, em razão da necessidade de manutenção do equilíbrio econômico-financeiro do contrato, resultarão em impactos orçamentários futuros.

Essa realidade não afasta a existência de um conflito jurídico a ser pensado e debatido. No mais, em um cenário de crescente contratualização da atuação da Administração Pública, não é desejável ou aceitável que esses contratos administrativos só possam ser cumpridos pelos vícios no ciclo orçamentário.

Considere-se, ainda, que esses vícios, embora apareçam como uma "solução" para as despesas relativas a obrigações contratuais, causam prejuízos em outras frentes, ao minar o planejamento realizado por meio das leis orçamentárias, reduzir a qualidade do gasto público e propagar a ausência de controle orçamentário, razão pela qual há diversos movimentos corrigi-los. Nesse sentido, apontam-se a consideração do orçamento base-zero, a defesa de maior participação do Poder Legislativo na elaboração das leis orçamentárias, a preocupação crescente com o planejamento da Administração Pública e a implementação do orçamento impositivo. 
Desse modo, são considerados alguns tópicos que, na correção desses vícios, podem contribuir para garantir a inclusão das despesas relativas às obrigações contratuais assumidas pela Administração Pública nas leis orçamentárias.

$\mathrm{Na}$ fase administrativa de elaboração da LOA, ou seja, na elaboração do seu projeto de lei pelo Poder Executivo, podem ser considerados: i) vinculação de receitas; ii) imposição normativa de inclusão dessas despesas; e iii) mudança da cultura da Administração Pública.

A vinculação de receitas para as despesas relativas a contratos administrativos pode vir tanto como garantia imprópria dos contratos de PPP quanto por meio de uma alteração do texto constitucional que crie mais uma exceção ao princípio da nãoafetação, a fim de garantir recursos públicos para essa finalidade. Contudo, é necessário ponderar a crítica feita às vinculações, em razão do engessamento por elas gerado no orçamento público e redução da discricionariedade do Poder Executivo para alocar recursos públicos de acordo com o programa de governo eleito.

Outra possibilidade para dar maior segurança à inclusão dessas despesas na LOA seria a criação de uma norma que imponha esse dever aos responsáveis pela elaboração do projeto de LOA, eventualmente prevendo uma sanção para o seu descumprimento. Nesse caso, a espécie normativa dependeria da abrangência objetivada pelo comando. Na mesma toada, seria possível uma alteração legislativa para exigir expressamente que todos os contratos administrativos cuja duração extrapole um exercício financeiro estejam de acordo com as diretrizes, os objetivos e as metas do PPA.

Ainda, deve-se considerar a possibilidade de que o conflito estudado nesse trabalho, no que tange à fase administrativa de elaboração das leis orçamentárias, possa ser resolvido com uma mudança na cultura da Administração Pública, no sentido de uma maior preocupação com a elaboração dos projetos das leis orçamentárias e com as diretrizes, os objetivos, as metas, os programas 
e as despesas neles incluídos. É o caso do Decreto $n^{\circ}$ 9.046/17 que cria um sistema informatizado no âmbito do Poder Executivo federal para registro e acompanhamento dos compromissos financeiros assumidos por contratos plurianuais, o que, embora não crie a obrigação de inclusão das respectivas despesas no projeto de LOA, certamente contribui para que não haja omissão motivada por falhas de planejamento e informação. Assim, as mudanças normativas consideradas acima, ainda que possam induzir essa mudança na cultura da Administração Pública, não são imprescindíveis.

Já na fase legislativa de elaboração da LOA, dois potenciais pontos de solução para o conflito se sobressaem: a proibição a emendas parlamentares e as dotações plurianuais.

O primeiro consiste na proibição de anulação de despesa relativa a contratos administrativos por emendas parlamentares, à semelhança do previsto para as dotações para pessoal e seus encargos e serviço da dívida. Para tanto, seria necessária uma emenda constitucional e, ainda, que tal emenda constitucional não fira a cláusula pétrea da separação de poderes. No mais, essa medida restringiria o campo de participação do Poder Legislativo na elaboração da LOA, formalizando um dos vícios do ciclo orçamentário que se pretende superar.

O segundo ponto seria a implementação de dotações plurianuais. Nesse caso, a autorização legislativa para as despesas relativas a contratos administrativos plurianuais seria dada, de uma única vez, pelo valor global do contrato, e válida para todos os exercícios financeiros de sua duração, retirando o risco de que as autorizações legislativas para a realização das despesas dos exercícios financeiros seguintes não sejam concedidas. Entretanto, a anualidade orçamentária é regra constitucional e, sendo a autorização legislativa um dos seus fundamentos, a implementação de dotações plurianuais provavelmente demandaria emenda constitucional. Diz-se "provavelmente" porque a proposta já integrou projeto de lei complementar e seria possível a interpretação de que, apesar da previsão de dotações plurianuais, o orçamento público continuaria a ser anual. 
Passando para a execução orçamentária, pontos possíveis para a solução do conflito em questão seriam a limitação da incidência de instrumentos de flexibilidade orçamentária, o carry-over e a implementação do orçamento impositivo.

O primeiro consiste na limitação do uso de instrumentos de flexibilidade orçamentária para postergar a execução de despesas relativas a contratos administrativos, o que reduziria os casos de reequilíbrio econômico-financeiro e os impactos orçamentários por eles gerados. Essa limitação pode ser implementada por alteração infraconstitucional, mas consistiria na concessão de um tratamento privilegiado dessas despesas em detrimento de outras, exigindo uma análise prévia de sua necessidade e adequação.

O segundo seria o carry-over, consistente na possibilidade de carregar dotações orçamentárias não usadas em um exercício financeiro para o seguinte. Por meio desse instrumento de flexibilização da execução orçamentária, seria possível adequar a execução de despesas públicas relacionadas a contratos administrativos plurianuais, ao viabilizar que a autorização orçamentária se adapte ao ritmo de execução desses projetos. De toda forma, o maior impacto do carry-over poderia recair sobre os contratos regidos pela Lei $n^{\circ} 8.666 / 93$ que têm a sua duração limitada à vigência dos créditos orçamentários, vez que o instrumento estenderia a própria vigência desses créditos. Para a espécie normativa adequada à introdução desse instrumento no ordenamento jurídico brasileiro, recorre-se às mesmas observações traçadas para a implementação de dotações orçamentárias plurianuais: seria necessária emenda constitucional ou lei complementar, a depender da interpretação que se tem da anualidade orçamentária consagrada pela Constituição Federal.

Uma solução definitiva do problema nesse ponto passaria pela adoção do orçamento impositivo, seja por uma mudança na interpretação constitucional das leis orçamentárias, por uma alteração normativa ou por uma mudança no comportamento da Administração 
Pública. Assim, as despesas seriam executadas tal como aprovadas pelo Poder Legislativo e previsto no cronograma de execução mensal de desembolso, reservando o uso dos instrumentos de flexibilidade orçamentária à excepcionalidade que lhes é própria.

No geral, o objetivo dessas sugestões é agregar maior segurança à execução dos contratos administrativos cuja duração ultrapasse um exercício financeiro, reduzindo os riscos para o particular e, por consequência, os custos para a Administração Pública, e garantindo que seus produtos sejam entregues sem entraves orçamentários.

A partir disso se coloca uma questão que tangencia esse trabalho e merece ser respondida para concluí-lo: afinal, os contratos administrativos devem se adequar ao orçamento público (e sua anualidade) ou o orçamento público deve se adequar aos contratos administrativos?

A regra da Lei ${ }^{\circ}$ 8.666/93 parece apontar para a resposta de que os contratos administrativos devem se adequar ao orçamento público. De fato, essa resposta parece, em um primeiro momento, a mais fácil, vez que afasta diversos pontos do conflito analisado nessa pesquisa.

Contudo, essa resposta é inadequada a contratos administrativos plurianuais, cada vez mais presentes na realidade da Administração Pública brasileira. Portanto, afirma-se que o orçamento público, enquanto LOA, deve se adequar aos contratos administrativos firmados pela Administração Pública, refletindo suas necessidades e seus compromissos financeiros.

Por outro lado, os contratos administrativos devem observar as diretrizes, os objetivos e as metas presentes no sistema orçamentário, enquanto ele reflete o planejamento da Administração Pública, no qual esses contratos administrativos devem se inserir e ao qual devem se conformar, espírito presente na LRF e consagrado na Lei ${ }^{\circ} 11.079 / 04$.

Isto posto, encerram-se as conclusões dessa pesquisa com a observação de que contratos administrativos e orçamento público podem auxiliar um ao outro a serem mais vinculantes (ou impositivos) 
e efetivos, se confirmando dentro de uma lógica de planejamento da Administração Pública do qual são instrumentos e reflexo. 


\section{REFERÊNCIAS BIBLIOGRÁFICAS}

ALMEIDA, Carlos Otávio Ferreira de. O planejamento financeiro responsável: boa governança e desenvolvimento no Estado contemporâneo. In: CONTI, José Mauricio; SCAFF, Fernando Facury (coord.). Orçamentos Públicos e Direito Financeiro. São Paulo: Revista dos Tribunais, 2011, pp. 577 - 599.

ALVES, Diego Prandino. Carry-over: a flexibilização do princípio da anualidade orçamentária como indutora da qualidade do gasto público e da transparência fiscal. In: Finanças Públicas - XVI Prêmio Tesouro Nacional, Tema II - Economia e Contabilidade do Setor Público, Brasília, 2011. Disponível em < https://www.tesouro.fazenda.gov.br/images/arquivos/artigos/Premio 2011_Tema_2_MH1.pdf >. Acesso em: 24 out. 2017.

ARAGÃO, Alexandre Santos de. A consensualidade no direito administrativo: acordos regulatórios e contratos administrativos. In: Revista Forense, Rio de Janeiro, v. 103, n. 389, p. 3 - 17, jan./fev. 2007.

- A concepção pós-positivista do princípio da legalidade. In: Revista de Direito Administrativo, Rio de Janeiro, v. 236, p. 51 - 64, abr./jun. 2004.

AURÉLIO, Bruno. Novos paradigmas na relação públicoprivado. Estudo de caso: as primeiras PPPs mineiras. In: Revista Brasileira de Infraestrutura, Belo Horizonte, v. 3, n. 6, p. 149 - 167, jul./ dez. 2014.

ÁVILA, Humberto. Princípios e regras e a segurança jurídica. In: RDE - Revista de Direito do Estado, Rio de Janeiro, v. 1, n. 1, p. 189 - 206, jan./ mar. 2006.

BALEEIRO, Aliomar. Uma Introdução à Ciência das Finanças. 12a ed. Rio de Janeiro: Forense, 1978. 
BASTOS, Celso Ribeiro. Curso de Direito Financeiro e Tributário. $9^{\mathrm{a}}$ ed. atual. e ampl. São Paulo: Celso Bastos Editor, 2002.

BAUDU, Aurélien. L'incertaine renaissance parlementaire em matière budgétaire et financière. In: Revue du Droit Public et de la Science Politique en France et à L'Étranger, Paris, n. 5, p. 1423 1450, sept./oct. 2010.

BENETON, Marco Antonio Hatem. O Plano Plurianual, os contratos administrativos e a Teoria do Diálogo das Fontes: os exemplos de elos entre o Direito Financeiro e o Direito Administrativo. In: CONTI, José Mauricio; SCAFF, Fernando Facury (coord.). Orçamentos Públicos e Direito Financeiro. São Paulo: Revista dos Tribunais, 2011, pp. $601-617$.

BINENBOJM, Gustavo. As parcerias público-privadas e a vinculação de receitas dos fundos de participação como garantia das obrigações do poder público. In: JUSTEN FILHO, Marçal; SCHWIND, Rafael Wallbach (coord.). Parcerias público-privadas: reflexões sobre os 10 anos da Lei 11.079/2004. São Paulo: Revista dos Tribunais, 2015, pp. $475-491$.

. O sentido da vinculação administrativa à juridicidade no direito brasileiro. In: ARAGÃO, Alexandre Santos; MARQUES NETO, Floriano de Azevedo (coord.). Direito Administrativo e seus novos paradigmas. Belo Horizonte: Fórum, 2012, pp. 145 - 204.

BITTENCOURT, Sidney. A questão da duração do contrato administrativo. In: Fórum de Contratação e Gestão Pública, Belo Horizonte, v. 2, n. 14, p. 1675 - 1681, fev. 2003.

BLIACHERIENE, Ana Carla. Orçamento Impositivo à Brasileira. In: HORVATH, Estevão; CONTI, José Mauricio; SCAFF, Fernando Facury (Org.). Direito Financeiro, Econômico e Tributário: Estudos em Homenagem a Regis Fernandes de Oliveira. São Paulo: Quartier Latin, 2014, pp. 49 - 71. 
BOUVIER, Michel; ESCLASSAN, Marie-Christine; LASSALE, Jean-Pierre. Finances Publiques. 12ème ed. Paris: LGDJ, 2013.

BRASIL. Ministério da Fazenda; Secretaria do Tesouro Nacional. Avaliação dos Restos a pagar - Ano 2017. Brasília, Ministério da Fazenda, 2017. Disponível em < file:///C:/Users/Giovanna/Downloads/Disserta\%C3\%A7\%C3\%A3o/ Textos/5-

\%20Princ\%C3\%ADpios\%20or\%C3\%A7ament\%C3\%A1rios\%20e\% 20anualidade\%20or\%C3\%A7ament\%C3\%A1ria/Relat\%C3\%B3rio \%20de\%20Avalia\%C3\%A7\%C3\%A3o\%20dos\%20Restos\%20a\%20 Pagar\%202017.pdf >. Acesso em: 24 nov. 2017.

BURKHEAD, Jesse. Orçamento público. Rio de Janeiro: Fundação Getúlio Vargas, 1971.

CÂMARA, Jacintho Arruda. Capítulo 3: o prazo nos contratos públicos. In: DI PIETRO, Maria Sylvia Zanella (coord.). Tratado de Direito Administrativo - Licitações e contratos administrativos, Volume 06. São Paulo: Revista dos Tribunais, 2014, pp. 339 - 353.

CAMPOS, Dejalma de. Direito financeiro e orçamentário. $4^{\mathrm{a}}$ ed. São Paulo: Atlas, 2006.

CAPATANI, Márcio Ferro. A discricionariedade do Poder Executivo na elaboração do projeto de lei orçamentária anual. In: CONTI, José Mauricio; SCAFF, Fernando Facury (coord.). Orçamentos Públicos e Direito Financeiro. São Paulo: Revista dos Tribunais, 2011, pp. 245 - 266.

CARVALHO, André Castro. Vinculação de receitas públicas e princípio da não afetação: usos e mitigações. 2010. 243 p. Dissertação (Mestrado em Direito Econômico, Financeiro e Tributário) Faculdade de Direito da Universidade de São Paulo, São Paulo, 2010. 
CARVALHO, André de Castro; LOCHAGIN, Gabriel Loretto; SILVEIRA, Francisco Secaf. Orçamento Público. In: OLIVEIRA, Regis Fernandes de et al (coord.). Lições de Direito Financeiro. São Paulo: Revista dos Tribunais, 2016, pp. 67 - 94.

CARVALHO, Daniel Bulha de. As influências da lei de responsabilidade fiscal nas licitações e contratos administrativos. In: Revista do Tribunal de Contas da União, Brasília, v. 42, n. 118, p. 25 - 34, maio/ ago. 2010.

CARVALHO, José Augusto Moreira de. O orçamento a partir de seus princípios. In: CONTI, José Mauricio; SCAFF, Fernando Facury (coord.). Orçamentos Públicos e Direito Financeiro. São Paulo: Revista dos Tribunais, 2011, pp. $81-109$.

CHRISTOPOULOS, Basile Georges Campos. Orçamento e a efetivação de direitos sociais. In: Revista Eletrônica sobre a Reforma do Estado, Salvador, n. 19, set./nov. 2009. Disponível em < http://www.direitodoestado.com.br/artigo/basile-georges-camposchristopoulos/orcamento-e-efetivacao-dos-direitos-sociais $>$. Acesso em: 24 nov. 2017.

COMPARATO, Fábio Konder. A Afirmação Histórica dos Direitos Humanos. $2^{\mathrm{a}}$ ed. rev. e ampl. São Paulo: Saraiva, 2001.

CONTI, José Mauricio. Flexibilidade orçamentária deve ser usada com moderação. In: Consultor Jurídico, 20 set. 2016, Contas à vista. Disponível em < https://www.conjur.com.br/2016-set20/contas-vista-flexibilidade-orcamentaria-usada-moderacao $>$. Acesso em: 24 nov. 2017.

. Crise econômica pode criar "orçamento recurso-zero". In: Consultor Jurídico, 8 mar. 2016, Contas à vista. Disponível em < https://www.conjur.com.br/2016-mar-08/contas-vista-criseeconomica-criar-orcamento-recurso-zero >. Acesso em: 24 nov. 2017. . E o ano começa sem a aprovação do orçamento federal. In: _. Levando o direito financeiro a sério. São Paulo: Blucher, 2016, pp. $101-104$. 
. Orçamento não pode mais ser uma peça de ficção. In:

. Levando o direito financeiro a sério. São Paulo: Blucher, 2016, pp. $115-119$.

- Vereador não pode apenas homologar a lei orçamentária. In: . Levando o direito financeiro a sério. São Paulo: Blucher, 2016, pp. 121 - 124.

. Natal é tempo de correr com a execução orçamentária. In: . Levando o direito financeiro a sério. São Paulo: Blucher, 2016, pp. $137-140$.

. Emendas ao orçamento e o desequilíbrio de poderes. In: L Levando o direito financeiro a sério. São Paulo: Blucher, 2016, pp. $145-148$.

. Hora é de "apertar o cinto" e contingenciar gastos. In: . Levando o direito financeiro a sério. São Paulo: Blucher, 2016, pp. $153-156$.

. Orçamento impositivo é avanço para administração. In: . Levando o direito financeiro a sério. São Paulo: Blucher, 2016, pp. $157-160$.

- Iniciativa legislativa em matéria financeira. In: CONTI, José Mauricio; SCAFF, Fernando Facury (coord.). Orçamentos Públicos e Direito Financeiro. São Paulo: Revista dos Tribunais, 2011, pp. $283-307$.

. Planejamento e responsabilidade fiscal. In: CONTI, José. Mauricio; SCAFF, Fernando Facury (coord.). Lei de Responsabilidade Fiscal: 10 anos de vigência - questões atuais. São José: Conceito Editorial, 2010, pp. 39 - 56.

(org.). Orçamentos públicos: a Lei 4.320/64 comentada. $2^{a}$ ed. atual. e rev. São Paulo: Revista dos Tribunais, 2010. 
. A autonomia financeira do Poder Judiciário. São Paulo: MP, 2006.

CORREIA, Marcelo Bruto da Costa. O prazo de vigência dos contratos administrativos de obras. In: $I O B$ - Repertório de Jurisprudência: Tributário, Constitucional e Administrativo, São Paulo, v. 1, n. 9, p. 303 - 308, maio 2010.

DALLARI, Adilson Abreu. Orçamento impositivo. In: CONTI, José Mauricio; SCAFF, Fernando Facury (coord.). Orçamentos Públicos e Direito Financeiro. São Paulo: Revista dos Tribunais, 2011 , pp. $309-327$.

DALLAVERDE, Alexsandra Katia. A atuação parlamentar no exercício do controle financeiro e orçamentário. In: CONTI, José Mauricio; SCAFF, Fernando Facury (coord.). Orçamentos Públicos e Direito Financeiro. São Paulo: Revista dos Tribunais, 2011, pp. 1235 -1253 .

FARIA, Rodrigo Oliveira de. PPA versus orçamento: uma leitura do escopo, extensão e integração dos instrumentos constitucionais brasileiros de planejamento. In: CONTI, José. Mauricio; SCAFF, Fernando Facury (coord.). Orçamentos públicos e Direito Financeiro. São Paulo: Revista dos Tribunais, 2011, pp. 661 $-691$.

Reflexão sobre o conflito entre princípios orçamentários. In: Interesse Público, Belo Horizonte, ano 12, n. 63, p. 95 - 102, set./out. 2010.

FERNANDES, Jorge Ulisses Jacoby. Duração dos contratos administrativos - novos paradigmas. In: Fórum de Contratação e Gestão Pública, Belo Horizonte, v. 10, n. 112, p. 23 - 28, abr. 2011.

FORTINI, Cristiana; PIRES, Priscila Giannetti Campos. Equilíbrio econômico-financeiro nas parcerias público-privadas. In: JUSTEN FILHO, Marçal; SCHWIND, Rafael Wallbach (coord.). Parcerias público-privadas: reflexões sobre os 10 anos da Lei 11.079/2004. São Paulo: Revista dos Tribunais, 2015, pp. 283 - 308. 
FRÓES, Fernando Oliveira. Finanças públicas, economia e legitimação: alguns argumentos em defesa do orçamento autorizativo. In: Revista de Direito da Procuradoria Geral do Estado do Rio de Janeiro, Rio de Janeiro, n. 64, p. 80 - 98, 2009.

FURTADO, José de Ribamar Caldas. O regime de execução da despesa orçamentária. In: Fórum de Contratação e Gestão Pública, Belo Horizonte, ano 7, n. 84, p. 45 - 47, dez. 2008.

GARCIA, Flavio Amaral. As parcerias público-privadas: prazo e prorrogação. In: JUSTEN FILHO, Marçal; SCHWIND, Rafael Wallbach (coord.). Parcerias público-privadas: reflexões sobre os 10 anos da Lei 11.079/2004. São Paulo: Revista dos Tribunais, 2015, pp. $579-608$.

GIACOMONI, James. Receitas vinculadas, despesas obrigatórias e rigidez orçamentária. In: CONTI, José Mauricio; SCAFF, Fernando Facury (coord.). Orçamentos Públicos e Direito Financeiro. São Paulo: Revista dos Tribunais, 2011, pp. 329 - 356.

Atlas, 2010. . Orçamento Público. $15^{\mathrm{a}}$ ed. rev. e atual. São Paulo:

GILLES, William. Les principes budgétaires et comptables publics. Paris: LGDJ, 2009

HABER, Michel; CHRISTOPOULOS, Basile Georges Campos; TORRES, Ricardo Ezequiel. Despesa Pública. In: OLIVEIRA, Regis Fernandes de et al (coord.). Lições de Direito Financeiro. São Paulo: Revista dos Tribunais, 2016, pp. 37 - 65.

HARADA, Kiyoshi. Direito financeiro e tributário. $18^{a}$ ed. São Paulo: Atlas, 2009.

HYNDMAN, Noel et al. Annuality in public budget - An explatory study. London: CIMA - The Chartered Institute Of Management Accounts, 2005. Disponível em < http://www.cimaglobal.com/en-gb/Thought-leadership/Research- 
topics/NHS-and-public-sector/Annuality-in-public-budgeting-anexploratory-study/ >. Acesso em: 24 nov. 2017.

JUSTEN FILHO, Marçal. A ampliação do prazo contratual em concessões de serviço público. In: Revista de Direito Administrativo Contemporâneo, São Paulo, v. 4, n. 23, p. 109 - 135, mar./ abr. 2016.

KANAYAMA. Rodrigo Luís. A ineficiência do orçamento público impositivo. In: Revista de Direito Público da Economia, Belo Horizonte, ano 7, n. 28, p. 127 - 144, out./dez. 2009.

LEBRÃO, Roberto Mercado; GOMES, Emerson Cesar da Silva. MOURÃO, Licurgo. Fiscalização Financeira e Orçamentária. In: OLIVEIRA, Regis Fernandes de et al (coord.). Lições de Direito Financeiro. São Paulo: Revista dos Tribunais, 2016, pp. 119 - 151.

LEITE, Harrison Ferreira. Segurança jurídica do orçamento público e sua alteração. In: Revista Tributária e de Finanças Públicas, São Paulo: Revista dos Tribunais, v. 19, n. 96, p. 153 - 180, jan./fev. 2011.

LIENERT, Ian; LJUNGMAN, Gösta. Carry-over and budget authority. International Monetary Fund, 2009.

LOCHAGIN, Gabriel Loretto. A execução do orçamento público: flexibilidade e orçamento impositivo. São Paulo: Blucher, 2016.

MACHADO, Dilmar Teixeira. A transparência na inscrição dos restos a pagar. 2012. 37 f. Trabalho de Conclusão de Curso (Especialização em Orçamentos Públicos) - Instituto Serzedello Corrêa, 2012.

MARÇAL, Thaís Boia. Por uma releitura do conceito de orçamento autorizativo no Brasil. In: BDA - Boletim de Direito Administrativo, São Paulo, v. 31, n. 3, p. 263 - 272, mar. 2015.

MARQUES NETO, Floriano de Azevedo. Do contrato administrativo à administração contratual. In: Revista do Advogado, 
São Paulo: Associação dos Advogados de São Paulo, ano XXIX, nº 107, p. $74-82$, dez. 2009.

MEDAUAR. Odete. $O$ direito administrativo em evolução. $3^{\mathrm{a}}$ ed. Brasília: Gazeta Jurídica, 2017.

. Direito Administrativo moderno. $14^{\mathrm{a}}$ ed. rev. e atual.

São Paulo: Revista dos Tribunais, 2010.

MENEZES, Dyelle. Recorde: "Orçamento paralelo" deve somar R\$ 240,1 bilhões em 2014. In: Contas Abertas, 04 jan. 2014. Disponível em

http://www.contasabertas.com.br/website/arquivos/7413 >. Acesso em: 24 nov. 2017.

MENEZES DE ALMEIDA, Fernando Dias. Contrato Administrativo. São Paulo: Quartier Latin, 2012.

- Mecanismos de consenso no direito administrativo. In: ARAGÃO, Alexandre Santos; MARQUES NETO, Floriano de Azevedo (coord.). Direito Administrativo e seus novos paradigmas. Belo Horizonte: Fórum, 2012, pp. 335 - 349.

- As parcerias público-privadas e sua aplicação pelo Estado de São Paulo. In: SUNDFELD, Carlos Ari (coord.). Parcerias Público-Privadas. São Paulo: Malheiros, 2011, pp. 563 - 581.

MONTEIRO, Vera. Concessão. São Paulo: Malheiros, 2010.

MONTEIRO, Vítor. Limites constitucionais à autonomia dos entes federados em matéria de contratos administrativos. 2014. 169 p. Dissertação (Mestrado em Direito do Estado) - Faculdade de Direito da Universidade de São Paulo, São Paulo, 2014.

. Interesse público e consensualidade administrativa - o caso dos contratos de parcerias. In: Fórum de Contratação e Gestão Pública, Belo Horizonte, ano 12, n. 134, p. 70 - 80, fev. 2013. 
MOREIRA, Vera Wolff Bava. As despesas públicas na virada dos exercícios financeiros. In: Revista da Escola Superior da Procuradoria Geral do Estado de São Paulo, São Paulo, v. 4, n. 1, p. 343 - 386, jan./ dez. 2013.

MOREIRA NETO, Diogo de Figueiredo. O futuro das cláusulas exorbitantes nos contratos administrativos. In: ARAGÃO, Alexandre Santos; MARQUES NETO, Floriano de Azevedo (coord.). Direito Administrativo e seus novos paradigmas. Belo Horizonte: Fórum, 2012, pp. $571-592$.

. Mutações do Direito Administrativo. $2^{\mathrm{a}}$ ed. atual. e ampl. São Paulo: Renovar, 2001.

NÓBREGA, Marcos. Orçamento, eficiência e performance budget. In: CONTI, José Mauricio; SCAFF, Fernando Facury (coord.). Orçamentos Públicos e Direito Financeiro. São Paulo: Revista dos Tribunais, 2011, pp. $693-728$.

NUNES, Selene Peres. Os 10 anos da LRF e o Projeto de Lei da Qualidade Fiscal. In: Cadernos da Controladoria, Rio de Janeiro, ano x, n. 2, set. 2010. Disponível em < http://www7.rio.rj.gov.br/cgm/comunicacao/publicacoes/cadernos/ed icoes/2010_09/anexos/caderno_09_2010.pdf. >. Acesso em: 24 out. 2017.

OLIVEIRA, Austen S. Restos a pagar. Orçamento. Lei de Responsabilidade Fiscal e seu art. 42. In: Revista Tributária e de Finanças Públicas, São Paulo, ano 19, n. 97, p. 67 - 97, mar./abr. 2011.

OLIVEIRA, Fernão Justen de. Garantias ao parceiro privado e comprometimento fiscal. In: JUSTEN FILHO, Marçal; SCHWIND, Rafael Wallbach (coord.). Parcerias público-privadas: reflexões sobre os 10 anos da Lei 11.079/2004. São Paulo: Revista dos Tribunais, 2015, pp. $459-473$.

OLIVEIRA, Regis Fernandes de. Curso de Direito Financeiro. $3^{\mathrm{a}}$ ed. rev. e atual. São Paulo: Revista dos Tribunais, 2010. 
PALMA, Juliana Bonacorsi de. Sanção e Acordo na Administração Pública. São Paulo: Malheiros, 2015.

PINTO, Élida Graziane. Controle judicial do ciclo orçamentário: um desafio em aberto. In: Interesse Público. Belo Horizonte, ano 17, n. 90, p. 199 - 226, mar./ abr. 2015.

- Judicializar o orçamento aprimorará as políticas públicas. In: Consultor Jurídico, 20 jan. 2014. Disponível em < https://www.conjur.com.br/2014-jan-20/elida-grazianejudicializarorcamento-aprimorara-politicas-publicas >. Acesso em: 24 nov. 2017.

PINTO JUNIOR, Mario Engler. O processo orçamentário no setor público: risco de inadimplência e alternativas de mitigação. In: JUSTEN FILHO, Marçal; SCHWIND, Rafael Wallbach (coord.). Parcerias público-privadas: reflexões sobre os 10 anos da Lei 11.079/2004. São Paulo: Revista dos Tribunais, 2015, pp. 439 - 457.

. Desafios para adoção do orçamento impositivo. In: Revista da Procuradoria Geral do Estado de São Paulo, São Paulo, n. 61/62, p. 77 - 95, jan./dez. 2005.

RIBEIRO. Leonardo Cézar. Impactos da anualidade orçamentária na alocação de recursos públicos. 2010. 42 f. Trabalho de Conclusão de Curso (Especialização em Orçamentos Públicos) Instituto Serzedello Corrêa, 2010. Disponível em < http://portal.tcu.gov.br/lumis/portal/file/fileDownload.jsp?inline $=1 \&$ fileId=8A8182A24F0A728E014F0ACCA5AD7689 >. Acesso em: 24 nov. 2017.

RIGOLIN, Ivan Barbosa; NUNES, Moacyr de Araújo. Emendas parlamentares ao projeto de orçamento. In: Fórum de Contratação e Gestão Pública, Belo Horizonte, v. 5, n. 55, p. 7441 7447, jul. 2006.

ROCHA, Francisco Sérgio Silva. Orçamento e planejamento: a relação de necessidade entre as normas do sistema orçamentário. In: 
CONTI, José Mauricio; SCAFF, Fernando Facury (coord.). Orçamentos Públicos e Direito Financeiro. São Paulo: Revista dos Tribunais, 2011, pp. $729-749$.

SABBAG, César de Moraes. Breves considerações sobre deficiências estruturais do sistema orçamentário brasileiro - Propostas para incrementar a legitimidade e a eficiência do modelo. In: CONTI, José Mauricio; SCAFF, Fernando Facury (coord.). Orçamentos Públicos e Direito Financeiro. São Paulo: Revista dos Tribunais, 2011 pp. $453-460$.

SANCHES, Osvaldo Maldonado. A participação do Poder Legislativo na análise e aprovação do orçamento. In: Revista de Informação Legislativa, Brasília, v. 33, n. 131, p. 59 - 77, jul./set. 1996.

SILVA, José Afonso da. Orçamento-programa no Brasil. São Paulo: Revista dos Tribunais, 1973.

SILVA, Moacir Marques da. A lógica do planejamento público à luz da Lei de Responsabilidade Fiscal. In: CONTI, José Mauricio; SCAFF, Fernando Facury (coord.). Orçamentos Públicos e Direito Financeiro. São Paulo: Revista dos Tribunais, 2011, pp. 751 - 765.

SILVA, Sebastião de Sant'Anna e. Os princípios orçamentários. Rio de Janeiro: Fundação Getúlio Vargas, 1962.

SILVA, Virgílio Afonso da. Direitos fundamentais: conteúdo essencial, restrições e eficácia. $2^{\mathrm{a}}$ ed. São Paulo: Malheiros, 2010.

SILVEIRA, Alexandre Coutinho da. Orçamento e planejamento: tensões entre poderes. In: Revista Fórum de Direito Financeiro e Econômico, Belo Horizonte, ano 4, n. 6, p. 31 - 58, set. 2014/ fev. 2015.

SUNDFELD, Carlos Ari. Direito Administrativo para céticos. São Paulo: Malheiros, 2014.

SUNDFELD, Carlos Ari; SOUZA, Rodrigo Pagani de; ROSILHO, André. As cláusulas de reajuste nos contratos públicos e a 
segurança jurídica. In: SUNDFELD, Carlos Ari; JURKSAITIS, Guilherme Jardim. Contratos públicos e Direito Administrativo. São Paulo: Malheiros, 2015, pp. 215 - 236.

TOLLINI, Helio Martins; AFONSO, José Roberto R. A Lei 4.320 e a responsabilidade orçamentária. In: CONTI, José Mauricio; SCAFF, Fernando Facury (coord.). Orçamentos Públicos e Direito Financeiro. São Paulo: Revista dos Tribunais, 2011, pp. 491 - 511.

TORRES, Heleno Taveira. Direito constitucional financeiro: teoria da Constituição Financeira. São Paulo: Revista dos Tribunais, 2014.

TORRES, Ricardo Lobo. Tratado de Direito Constitucional, Financeiro e Tributário, Volume V: o orçamento na Constituição. $3^{\mathrm{a}}$ ed. rev. e atual. Rio de Janeiro: Renovar, 2008.

VARGAS, Ângelo Miguel de Souza; PERIN, Mônica Waideman; GODOY, Murilo. Princípio da anualidade orçamentária aplicado ao prazo dos contratos administrativos regidos pela Lei 8.666/93. In: Revista Tributária e de Finanças Públicas, São Paulo, v. 17, n. 87, p. 11 - 65, jul./ ago. 2009.

ZANCHIM, Kleber Luiz. PPP e orçamento público - uma análise da Portaria $n^{\circ}$ 614/06, da STN, à luz da Lei no 4.320/64 e da Lei de Responsabilidade Fiscal. In: Fórum de Contratação e Gestão Pública, Belo Horizonte, v. 6, n. 68, p. 57 - 70, ago. 2007. 